\title{
EL RETO METANARRATIVO EN CONSPIRACIÓN DE GLORIA ELENA ESPINOZA DE TERCERO
}

\author{
Luis A. Jiménez
}

\begin{abstract}
RESUMEN
Conspiración, la novela más reciente de Gloria Elena Espinoza de Tercero, es un ejemplo típico de la metaficción. En este estudio, analizamos la relación del narrador con (1) América, la protagonista que proclama su autonomía en el texto (2) los personajes reales que se comunican con el narrador mediante correos electrónicos y (3) la escritora, que implícitamente reclama su autoría e ignora el reto de la voz narrativa.

Palabras clave: metanarrativa, narrador, autoría, omnisciencia, correos electrónicos.
\end{abstract}

\begin{abstract}
Conspiración, the most recent novel of Gloria Elena Espinoza de Tercero, is a typical example of metafiction. In this study, we analyze the relationship of the narrator with (1) América, the protagonist who claims her autonomy in the text (2) the real characters who communicate with the narrator by means of e-mails and (3) the writer, who implicitly claims her authorship and ignores the challenge of the narrative voice.

Key words: metanarrative, narrator, authorship, omniscience, emails.
\end{abstract}

Toda metanarrativa exige un análisis metacrítico por parte del investigador de un texto literario. El lector, pues, se apoya en el "sistema de significantes del autor" (lo que "quiere decir"), contiguo a "otros sistemas de significantes" (el texto crítico), o sea, la metacrítica que tiene a su cargo realizar (Kaelin 1999: 3- 27), e interpretar eso que se expresa, no el sentido de cómo lo expresa. En Conspiración (2007), la cuarta novela de Gloria Elena Espinoza de Tercero, la metaficción se remonta a su tercera obra Túnica de lobos (2005). Al hablarle al libro mismo, la protagonista María Esperanza, en su postura metatextual anuncia: “¡Hola libro! Estamos comenzando tu cuarto tomo” (2007: 332). En este gesto de metaficción, acoge la perennidad de un discurso novelístico que continúa en Conspiración.

Luis A. Jiménez. Doctor en Literatura Hispanoamericana. Universidad de Tampa, Florida. Estados Unidos de América. Correo electrónico: LJIMENEZ@ut.edu

Recepción: 14- 7- 2008

Aceptación: 8- 8- 2008 
Esta clave lingüística inacabable hacia el infinito, ya que nunca se cierra ni se termina, constituye una estructura abierta, que la autora tampoco pretende detener (Jiménez 2007: 199). Vale añadir que en sus dos novelas anteriores: La casa de los Mondragón (1998) y El sueño del angel (2004) existe el proyecto inicial y progresivo de la metanarrarativa por lo que respecta a la temática repetitiva y la intromisión de la autora en la presentación de personajes previos, en particular don Fito, que reaparecen consistentemente en discursos posteriores. Dicha intromisión en Conspiración, como en muchas otras obras escritas en español descarta la "muerte del autor" que propone Roland Barthes ${ }^{1}$.

La continuidad y la intertextualidad que salpican a Conspiración merecen una lectura metanarrativa ${ }^{2}$. Esta intertextualidad, según el juicio del crítico norteamericano Jonathan Culler, es una "modalidad de percepción", una manera de descifrar la obra literaria por parte del lector, que en su lectura y participación activa de la narración, identifica otros textos u otras voces que señalan y contribuyen a la calidad del libro en cuestión (1981: 103). En cuanto a esta gratificación, para Manuel Picado la producción textual se garantiza solamente como resultado de una lectura graficante del lector mismo. En su opinión, en la operación del metalenguaje el discurso "se arroga la potestad de hablar sobre otro para explicarlo (1983: 85- 86). Con respecto al intertexto, contingentemente aparece a menudo el metatexto cuando el/la autor/a interviene abiertamente en el proceso narrativo en un intento de verosimilitud ${ }^{3}$. Dicho de otro modo: en Conspiración la escritura mantiene su poder autorial en el manejo del narrador, la figura central América y otros personajes reales e imaginarios del relato que se acomodan a la empresa novelística basada hasta cierto sentido en la intertextualidad.

¿Por qué interviene la autora en Conspiración? Desde el punto de vista metacrítico, además de la reclamación de la autoría, implícitamente intenta despojar al narrador de su reto a la omnisciencia. Para Oscar Tacca, esta voz omnisciente es el "autor-dios" que se coloca por encima de los personajes porque lo sabe y descubre todo en el relato (1973: 73). En primer lugar, la supuesta intervención autorial crea la confusión de este narrador que está lidiando en una actitud dialógica con los personajes de la novela, sobre todo América, la figura principal de la trama. Segundo, permite la actuación de otros personajes reales, amigos o conocidos de Gloria Elena, que participan en la narración por medio de los socorridos correos electrónicos al narrador. Por último, causa que el narrador se enfrente a la autora porque teme perder terreno en su función jerárquica en el discurso. Claro está, en su disimulo la creadora dispone lo que el narrador cuenta "para decir lo que ella quiere que diga" (2007: 72), el desafío del significante, aunque "no es diosa" (2007: 90) tampoco.

\section{El narrador y América}

La posición inical del narrador en Conspiración equivocadamente parece colocarlo dentro de la técnica discusiva de tercera persona, predominante en el apogeo decimonónico de la novela. Ahora bien, a diferencia de ella, la percepción y captación de la ubicuidad tempoespacial se transforma en la segunda página del libro. La voz narrativa, muy a lo Cervantes, se desvía del relato para dirigirse a los lectores y declararles el objetivo de la escritura y ofrecerles datos sobre la protagonista: "Y ustedes se preguntarán: ¿Cuál es su cometido? Pues... narrarles la vida y milagros de América" (2007: 24).

La marcada presencia del "ustedes", también rasgo unamuniano que cuenta con el lector e intenta comunicarse con éste, a lo largo de la novela instaura las coordenadas 
entre la escritura y la lectura. Ambas se complementan y se hacen reversibles, otro reto de la metanarrativa, que en esta instancia cede su puesto a la interrogación: el propósito serio de la narración de la vida de América. Como si fuera un contrato, el narrador se dirige a su destinatario, atrapado en las redes del lenguaje, y sin entrar en juego con él porque no es su juguete gratuito. La pregunta también asoma un artificio ilocutorio de confabulación (o conspiración) con el interlocutor para que no lo tracione mientras lee.

Acto seguido, el narrador traba la pasión de América por León, su ciudad natal, al proceso de intextualidad. Se apodera del intertexto de un poema de don Jorge Arellano donde menciona la obstención y la gloria de los "viejos esplendores" (24) por el encanto del sitio. Aparte de la descripción minuciosa de América que lleva a cabo, la voz narrativa se centra en su cabello que se asemeja al de "Angélica María, cantante de los años 60 del cine mexicano" (25). Por un lado, el intertexto televisivo sirve justamente de artefacto discursivo para dar más verosimilitud a lo que le "quiere decir" al lector con poca explicación. Por el otro, crea cierto efecto paródico en el segmento narrativo que causa risa. En 2007, el peinado anticuado de la protagonista, que imita a la gran actriz, resulta anticuado, una tomadura de pelo que relaja al lector por su humor.

De repente, el narrador se entromete en la actividad teatral que la maestra América practica con sus estudiantes de drama. En un juego lúdico con el lenguaje marca el territorio discursivo que se le ha asignado en la novela. Vuelve a dirigirse al lector para afirmar la veracidad de una ficción que en realidad no existe, puesto que América es concebida por la autora y, por eso, carece de cohesión verosímil por mucho que se parezca a cualquier personaje real. Mientras tanto el narrador explica la distinción anatómica entre él y la protagonista en términos de género:

\footnotetext{
A mi entender, lo sé todo. Soy narrador omnisciente. En cambio América... es cierto que real y verdadero, vive en la ciudad de León como ya saben, pero ha sido concebida, destinada para ser la protagonista. Y con perdón de ustedes yo mismo no tengo figura...¿soy? ¡Pero mi sentir es masculino ¡Mi género es masculino! (2007: 27).
}

La disyuntiva del narrador estriba en el hecho que no puede contar con América, personaje liberado por la autora para reclamar su rol en el texto. Tal vez sea por ello que la declaración de su misión discursiva sea "distraer a los lectores, dis-tra-er-los. Me debo a los lectores, debo contar en la forma que a ellos les guste, sin comprometerme con nadie" (2007: 52). En esta instancia refuerza su pacto: el nexo entre él y el público ávido de participar en una lectura amena. Con el entretenimiento, justifica un modo de confabularse con el lector y con su presencia conspirar contra América, debido a la autonomía que la protagonista ya ha asentado en la obra.

Digamos de paso que la protagonista lleva el nombre de su continente, por ser la única mujer entre cuatro varones. Aquello que se nombra contiene ciertas pecularidades: nominativa (América), descriptiva (mujer) y designativa (continente). El personaje se proyecta en la novela como "género femenino", mujer independiente, arrogante y hasta dominante, lo que complace al narrador que, por lo visto, le gusta ser dominado. Para él, la pugna entre los sexos representa un desafío genérico, reiterado en el texto en varias ocasiones. América, en cambio, admite abiertamente que la autora no puede manipularla a su antojo, aspecto primordial de la metaficción porque el personaje se subleva contra la autoridad de la escritora. Este decreto de autonomía del personaje, proclamado y generalizado por los novelistas occidentales después de la primera guerra mundial, es una declaración de la inocencia de la autora que está creando 
una especie de teoría literaria en el texto. En todo caso, el narrador es también un personaje del libro pero irónicamente carece de esta autonomía.

En un breve planteo metacrítico que proviene de América, la protagonista expone repetidamente que si la escritura existe es por la sencilla razón que las criaturas ficticias se liberan de la voz autorial. Así, por lo menos, lo apunta en uno de sus diálogos breves con el narrador: "Se hace nuestra voluntad o no hay novela, historia, cuento o lo que sea" (2007: 28). Sugiere, entonces, que sin personajes no hay obra literaria, con o sin la actuación del narrador. Agreguemos también que la postura dialógica de América es de orden performativo que no tolera la omisión voluntaria de lo que debe decir. No obstante la rebelión de América, su opinión es parcialmente errónea.

A diferencia de América que consta de su nombre propio, el narrador no tiene el suyo. El despojo del nombre propio no resuelve en lo absoluto la crisis de identidad acosante que padece y lo mantiene, según él, en el anonimato. La anonimia no le otorga garantía a su estatuto debido al deseo de la autora de refenarlo. Por eso, se elimina la esfera de privilegio del narrador que tampoco puede monopolizar todos los puntos de vista, prueba que deambula en un espacio restringido y de poco poder escritural en el texto.

En resumidas cuentas, América termina aliándose al narrador, no porque se encuentre enamorada de él, sino para conspirar contra la autora. En el episodio dialógico que se desarrolla, llega al convencimiento que ambos están "a merced de una mujer" (2007: 154). El narrador, por su parte, asegura que la autora le ordenó hablar con la protagonista sobre un ensayo de teatro, afirmación autorial no confirmada en el texto. Por eso, carece de validez pues pudiera ser un sutil engaño discursivo. En ningún momento la autora debate o se enfrenta a ambos. El narrador al final de la obra se escuda interrogándose si algún día tendrá la oportunidad de verse "cara a cara con ella" (2007: 160).

\section{El narrador y otros personajes reales}

También el narrador puede asumir la función de personaje o dejar el punto de vista en manos de este. Sin embargo, en Conspiración ocurre algo realmente insólito: surgen personajes reales, con lo que la narración gana en vibración humana y cada uno de ellos expresa una visión del mundo diferente, cierto caudal informativo inmenso en el libro. Con estos personajes de "carne y hueso" inmersos en el texto, la óptica del lector exige una mayor participación, una posible confabulación con ellos, para decantar lo que se "quiere decir", ya que el narrador ha perdido su omnisciencia por completo y se siente defraudado, menospreciado.

La curiosidad del lector descansa en el desciframiento de lo que el "confidente", como lo llama el narrador reiteradamente en el texto, "quiere decir". Pretende que este destinatario interno lo ayude en la búsqueda de su "figura". Se imagina que mediante notas confidenciales pueda establecer una confabulación con los personajes reales, y quizás así conspirar mejor contra la autora. De hecho, el desfile de "confidentes" en el libro expresa una ironía porque son todos amigos o individuos que la autora conoce, por supuesto. Ellos actualizan y elaboran lo que el narrador desea escuchar o no, discursos metatextuales que son productos, dígase calcos injertados por la escritora.

Con la actuación de personajes reales, el narrador renuncia totalmente a su sabiduría omnisciente, debilitada porque no puede saber más que ellos. Se sustituye, pues, la "realidad" captada por la voz narrativa por otra "realidad" expuesta por las voces discursivas de personajes 
que existen y, en cierto sentido, manipulados, por la ingerencia de la autora. Se convierten en una copia del original sumergida en el texto para transformar la ficcionalidad del relato en boca de personajes que conspiran con la autora y dicen o desdicen lo que ella "quiere decir"4. Estas personas ven, cuentan y le hablan al narrador a su estilo, llevan algo de la intimidad de la escritora. Encarnan la vida, la cultura y la literatura de espacios distintos, corporizados en el lenguaje como cualidad significativa de la metaficción.

¿Por qué utilizan el socorrido correo electrónico para escribirle al narrador? En contraste con el género epistolar, caracterizado por el método lento de recibir y contestar cartas, es el modo más factible en el mundo postmoderno de pasarle rápidamente una opinión o darle consejos prácticos con una variedad de temas vinculados estrictamente a la posición de la voz narrativa en la novela.

En el primer correo electrónico que el narrador remite a sus posibles "confidentes", se queja que "la autora no me describe ni nadie" (2007: 27). Por esta razón se dirige a ellos con pertinencia para que le brinden una descripción o, más específicamente una "figura". En la redaccción del mensaje les pide que entren en el correo de la autora con el siguiente anuncio: "Puede enviarme un dibujo, un fotomonteaje, un identikit" (2007: 27).

Algunos de los correos van dirigidos a la relación entre el narrador y América. El contenido de los mismos da risa porque están cargados de chistes sobre la sexualidad femenina. Delatan que la protagonista es una mujer fuerte, que "está como quiere", y que "conmigo estará en buenas manos" (2007: 33). En este ultimo, prevalece el humor, debido a que el remitente le va a escribir un poema a América donde se convierte en "savia, [y] así podremos fundirnos con amor clorofílico" (2007: 33).

Entre los otros correos que recibe el narrador se alaban su simpatía, el cáracter varonil que lo caracteriza con la intención de exaltar su ego machista moderado e irónicamente se destacan su cualidad de "pendejo" y de "maricón" con las mujeres, especialmente hacia América. Sobresale el chiste en latín de Luis Alberto Tercero sobre el zopilotorum, pero no se explica. Causa risa el segmento cómico impregnado de sexualidad que envía el piruca Picado sobre Ameriquita. El choteo aquí podría denominarse de diatriba, o sea, la sátira violenta al ego masculino, causante del rebajamiento del sujeto. Responde Picado con su consejo: “y vas a ver cómo te entiende la condenada: venite morenita, dejá que te llene de mi locura, que te rempuje para que sepás lo que un hombre te puede hacer" (2007: 69).

Por medio de la parodia, el piruca Picado se burla y ataca al narrador cuando emplea los versos ajenos de Pablo Antonio Cuadra, Gloria Gabuardi, Christian Santos y Jorge Luis Borges en su enamoramiento arcaico con América ${ }^{5}$. Por su naturaleza imitativa y repetitiva, el recurso paródico instala un discurso carnavalesco y escatológico, comúnmente expresado en la lengua popular, sin pertenecer tampoco al oficio juglaresco que se discute en la novela. Reproducimos parte de esta otra voz explicativa, mezcla de humor y malicia:

\footnotetext{
Qué darías zompenco por declarar el amor con versos propios. Ya me tenés hasta la verga, ni sé por qué te sigo leyendo. Donde las conejitas te voy a enseñar la geografía del cuerpo humano. Y con los taladros que nos dotó la naturaleza, escarbaremos para descubrir ¡el paraíso! ¡Animal! Te dejo con tus mierdas... me voy por la pantalla donde mamacita (2007: 73).
}

Con mucho más detalles, el de María Amoretti, profesora de la Universidad de Costa Rica e íntima amiga de la autora, se refiere también con ironía a una "hombría" pese a que las mujeres lo asustan. El doble sentido estriba en el hecho que el narrador es ficticio y no puede ser hombre, la que existe es la autora mujer que lo manipula al extremo y no le tiene miedo. 
Le explica que su confusión resistente se opone a otra pluma femenina, ansiosa de encontrar "su verdadera expresión en medio de toda una tradición escritural masculina" (2007: 50). De ahí, la reafirmación de la dicotomía hombre-narrador / mujer-autora (no olvidemos a Américamujer-personaje) que permea en la obra, la pugna de género que ya hemos analizado.

En la nota, Amoretti compara al narrador con el símil de un travesti con dos máscaras: una rosada y otra celeste, cuyo desprendimiento puede mostrar su verdadero rostro. En nuestro juicio, el travesti se convierte en hombre / mujer o viceversa, y detrás de la imagen se esconde una persona real. La máscara es sencillamente un doble ropaje, una ilusión que padece la voz narrativa, por ser ficticio y no un hombre y por el empeño de sentirse equívocamente superior a una mujer escritora que existe. Consciente de la humillación, la pretensión de desemascararlo significaría despojarlo aún más de su rol como narrador y darle la razón a la autora, mujer admiradora del Azul rubendariano. Casi al final, se establece un intertexto cromático con Federico García Lorca: "verde que te quiero verde" (2007: 50), muy distinto a los otros colores de la máscara anterior. En cuanto a este color, transforma la tonalidad de la máscara a un "universo verde" que puede remontarse al mundo imaginado recreado por el narrador con Amelia, o tal vez el de la esperanza y la utopía del sueño latinoamericano presente en el proyecto de nación en la novela.

Después de engraciarse con el narrador por su ingenuidad, el tercer correo de Amoretti penetra en el conflicto entre "causa" y "efecto". Debido al proceder del narrador, este provoca en él el desconcierto ajeno incitado por la barrera entre "la ficción" y la "realidad", la metanarrativa de la obra. Explica el caso en esta nota que es verídica: "henos aquí conversando los seres reales con los seres de papel, los narradores metidos a personajes y los lectores metidos a escritores" (2007: 92). Acude al "signo de Batjín", la polifonía de voces y la relativización del lenguaje del discurso que despojan toda fuerza autorial, absoluta y monológica, teoría literaria del crítico ruso. Se discute la imagen especular, conciencia propia de la autora y fantasma del narrador. En este mensaje alentador y conspirando con él, la voz discursiva concluye diciendo que el problema es de la escritora no de él, la "diferencia genérica" saliente en el texto (2007: 92).

Desde Costa Rica, el correo de Miriam Villalobos establece la diferencia entre América, símbolo para las mujeres por su liberación, y la autora, que según opina "no tiene el mayor respeto por su género" (2007: 89), reiteración que la protagonista se encuentra "a merced de una mujer" en el libro. Le aconseja al narrador que se ajuste los pantalones para defender su amor y detener la conspiración de la escritora. Por otro lado, Isolda Hurtado, Directora Ejecutiva de ANIDE, conspira con la autora y sale en defensa de ella por considerarla una de las socias fundadoras de la organización. Dentro de su postura feminista, no respalda al narrador porque los hombres "tienen de sobra a quienes recurrir para defenderse" (2007: 90), otro planteamiento obvio de la dicotomía genérica que se sustenta a lo largo de la novela.

Estos correos electrónicos y muchos más indican ampliamente el mundo dialógico y polifónico del texto. El sentido de la novela se nutre del enfrentamiento eslabonado entre voces diferentes que se oponen y se retan entre sí.

\section{El narrador y la autora}

La intervención inplícita de la escritora en el texto la convierte en cómplice confabulado del mismo, en función indirecta pues no entra en la puesta en escena. Al mismo tiempo, reta al lector para que conspire junto a ella y contra el narrador en el goce previsible de lo escrito y lo leíble. La función metalingüística de esta voz autorial forma parte de un doble 
propósito en el alcance de la comunicación: con el narrador que controla y con el lector de la obra, y que tampoco puede manipular ${ }^{6}$. El autor es sencillamente un componente más en el funcionamiento de un sistema de lenguaje escrito, atado a otros sistemas de diversas índoles, pero siempre a favor de los significantes. En otras palabras, el goce desafiante de la lectura de Conspiración radica en estos significantes, en lo que se "quiere decir", no en el contenido del texto, los significados que puedan existir en este.

Los primeros indicios de la existencia de la autora ocurren en el episodio inicial entre el narrador y América. El narrador aparece sin nombre, indicación de la preferencia de la autora por nombrar sólo al género femenino, la protagonista. La voz narrativa justifica la confusión del encuentro con América debido a "un lapso de la autora, no mío. No tiene sentido que se entrometa en mi narración" (2007: 26). No entiende por qué la autora no lo ha descrito en el libro, y por esta situación denigrante se siente cosificado como "un bombillo, un cartel, una caricatura, un accidente, algo secundario, no esencial" (2007: 27). Al defender su jerarquía, ataca asimismo a la escritora basado en una acusación genérica: "¡Mujer! que "hasta el momento ni siquiera me ha dirigido la palabra", es "batuta de una organización, no su directora" (2007: 27-28).

En los comentarios sobre tratamiento de la autora, el narrador se arma de artificios metaficcionales propuestos a menudo de una manera risible. Es como si se saliera del texto para revelarse contra la escritora que lo controla en su totalidad: "mi autonomía es cero. La autora dispone de mí a su gusto y antojo... Me menosprecia, no hay duda" (2007: 28). Continúa admitiendo su hombría como suficiencia absoluta, pero más que hombre reclama su función de narrador en el libro. También por pertenecer al género masculino y en actitud machista, pretende ganársela con la persuasión de su poder seductivo. No lo logra, ni el plano físico ni en el discursivo. Por ello, depende de los correos electrónicos de los personajes reales en búsqueda de la reafirmación de su papel y resolución a su crisis de identidad.

Recordemos que todo narrador es una abstracción y tiene un cáracter ficticio. Carece de personalidad o de "figura" como se reitera en la novela. Cuando le habla al lector confiesa: "con perdón de ustedes, yo mismo no tengo figura ... ¿Soy?" (2007: 27). Las explicaciones, filtradas aquí y allá en la obra, nos permite adivinar una condición ontológica nula puesto que no es real. Por lo general, el papel del narrador es simplemente contar para peculiarizar la historia. A diferencia de Niebla, donde el narrador, al igual que Unamuno son hombres, en Conspiración la conducta del narrador es inusitada y se niega a aceptar la subordinación masculina a la superioridad de la autora, una mujer. Esta insubordinación explícita apunta hacia el terreno de la metaficción que es el objetivo principal de la autora al escribir el libro.

Contrariamente a Niebla de Unamuno, en esta otra novela la escritora no interviene directamente en las pugnas que plantea el narrador en el relato. Por el contrario, no le hace caso porque su intención primaria es anular la omnisciencia de la voz narrativa. En suma, la última voz que prevalece es el de la "figura" autorial para cumplir así su cometido metanarrativo. Cabe añadir finalmente que la labor performativa del narrador, América y los personajes reales se interfieren continuamente sin que podamos aislarlos. Contribuye al reto metanarrativo urdido por la creadora en el acto de escritura.

A modo de palimpsesto, al final del discurso narrativo el lector o el metacrítico de Conspiración llega a la conclusión que el libro permanece en su forma digital, está publicado o anda en camino de su publicación, o sea, implica la existencia de un manuscrito: "La autora rompe el borrador que termina de leer y lo tira al cesto de la basura" (2007: 161). Ya en otro 
previo gesto ilusivo de la lengua, se ha incluido la opinión generosa del que ahora escribe poniendo en su boca lo siguiente: "Me encanta la historia" (2007: 114), de este cuarto tomo anunciado por María Esperanza en Túnica de lobos. El pronunciamiento es una invitación autorizada a tener acceso, me autoriza ya hablarle al texto publicado mientras que le digo con objetividad que es un libro ameno, lúdico hasta la risa en ciertas ocasiones e insólito por lo que "quiere decir". A través de la lectura, he conspirado conjuntamente con el placer que brinda el reto metacrítico de la escritura de Gloria Elena Espinoza de Tercero.

\section{Notas}

1. Cuando Michel Foucault habla en su artículo sobre el concepto de autor, se refiere a su inmanencia en función de discurso mientras cuestiona la "figura" autorial que simplemente refleja la formación del "yo" (1979: 141- 60).

2. En la "Introducción" a Conspiración Jorge Chen Sham realiza un breve estudio metacrítico entre la novela y Niebla de Miguel de Unamuno (2007: 8- 22).

3. María Amoretti Hurtado afirma que la presencia autorial de la "figura del autor" es un principio fundacional en el texto y legitima la "verdad" de su existencia gracias al lenguaje (1998: 15).

4. María Amoretti me proporcionó el dato que los correos electrónicos suyos fueron escritos por ella a partir de su lectura del manuscrito. De otra manera, el lector no hubiera tenido la veracidad de esta información.

5. Para Freud, el gesto lúdico del bromista es jactarse de su inteligencia, sobre todo, de la urgencia de igualarse como exhibicionista en el terreno de la sexualidad (2003: 138).

6. Como subraya Umberto Eco, la comunicación textual "por fuerza influye en el universo del hablar, del significar, del comunicar" (1977: 68- 69).

\section{Bibliografía}

Amoretti Hurtado, María. 1998. "Autor y autoridad...Cuestión de principios”. Káñina, Revista de Artes y Letras, Universidad de Costa Rica. 22 (1): 9- 21.

Barthes, Roland. 1987. “La muerte del autor”. Susurro del lenguaje. Barcelona: Paidós.

Culler, Jonathan. 1981. "Presupposition and Intertextuality,” The Pursuit of the Signs. Ithaca: Cornell UP.

Eco, Umberto. 1977. Tratado de Semiótica General. Barcelona: Editorial Lumen.

Espinoza de Tercero, Gloria Elena. 1998. La casa de los Mondragón. León: Editorial Universitario UNAM-León. 
2005. El sueño del ángel. Managua: Editorial PAVSA.

2005. Túnica de lobos. Managua: PAVSA.

2007. Conspiración. Managua: Centro Nicaragüense de Escritores.

Foucault, Michel. 1979. "What is an Author". Textual Strategies: Perspectives in PostStructuralist Criticism. Josué Harari (ed.). Ithaca: Cornell UP, 141-60.

Freud, Sigmund. 2003. The Joke and Its Relation to the Unconscious. Joyce Crick (trad.). New York: Penguin Books.

Jiménez, Luis A. 2007. "Espacios narrativos en Túnica de lobos". De casas, ángeles y lobos. Jorge Chen Sham (ed.). León: Universidad Nacional Autónoma de Nicaragua, 185- 199.

Kaelin, E.F. 1999. Texts on Text and Textuality. A Phenomenology of Literary Art. Amsterdam: Rodopi.

Picado, Manuel. 1983. "La literatura: entre el diálogo y la metalengua". Káñina, Revista de Artes y Letras, Universidad de Costa Rica. 7 (1): 85- 90.

Tacca, Oscar. 1973. Las voces de la novela. Madrid: Gredos. 